\title{
CAMPIONI, Giuliano. Nietzsche e o espiríto latino. (São Paulo; Edições Loyola, 2016)*
}

\author{
Stefano Busellato**
}

À díade que parecia inalcançável, ou seja, os nomes de Colli e Montinari, na Europa, se acrescenta cada vez com mais frequência o nome de Campioni, e isso tem as suas razões de ser. Talvez um dos textos mais importantes de Campioni, que chega aos leitores brasileiros através das Edições Loyola na coleção Sendas \& Veredas, é uma valiosa demonstração. Desejado com previdência e acuidade e coordenado por Scarlett Marton, autora de uma "Apresentação à edição brasileira" (p.10-18) muito bem informada, traduzido com bom gosto por Vinicius de Andrade, Nietzsche e o espírito latino não apresenta só um estudo que poderá tornar-se referência para muitos pesquisadores que se dedicam ao pensamento do filósofo alemão. Esse trabalho contém algo que vai além do que se pode razoavelmente esperar de uma simples monografia. É o exemplo de uma metodologia, de uma relação peculiar, direta e íntima, com as páginas nietzschianas. Um trabalho de escavação, reconstrução e descobertas que oferece, no seu término, não uma figura-Nietzsche (operação sempre empobrecedora e frequentemente falsificadora), mas o percurso-Nietzsche.

Esse percurso conduz propositalmente para longe das insalubres leituras rápidas, construídas mais por preconceitos, equívocos e exageros e não pela real necessidade de entender o pensamento

\footnotetext{
* Tradução de Ademir Menin.

** Pós-doutorando na Universidade do Oeste do Paraná, Unioeste, PR. Correio eletrônico: stefano.buselatto@email.it.
} 
Busellato, S.

de Nietzsche, como acontece aos "muitos que fruem esteticamente e em modo imediato do filósofo na busca de mestres absolutos de sapiência ou profetas do nihilismo" (p. 29). O que aqui se desmente é sobretudo a imagem caricatural e difícil de fazer desvanecer do Nietzsche germânico, o fato de fazer-lhe dizer o "Deutscheland über alles" fazendo-lhe portar chapéus nibelungos e gritar a chegada de um Übermensch de olhos claros e de farda escura, como o próprio autor já se lamentava em Ecce Homo contra aqueles que apostrofava de "doutas bestas".

Se a contribuição do texto fosse só essa, seria já um mérito, pois mérito é o fato de corrigir um erro de modo definitivo. Mas a demonstração do espírito latino de Nietzsche contra o mito germânico do Volk não se limita a isso. Reunindo idealmente as testemunhas onde o mestre Montinari mesmo tinha interrompido a sua pesquisa, isto é, iniciando a delinear o horizonte provençal e meridional como a melhor contestação do Nietzsche provincial e nacionalista ${ }^{3}$, Giuliano Campioni não só devolve o real diálogo através do qual se constituiu o pensamento nietzschiano, mas oferece um vasto panorama da cultura dentro da qual tal pensamento toma precisão, espessura e originalidade.

Esse é um outro Nietzsche em relação às interpretações "que só fazem tecer repetidamente uma discutível trama de filosofemas, sem nenhuma referência concreta à realidade da vida intelectual de Nietzsche"4. Nisso Campioni consegue os próprios resultados com aquilo que hoje, graças também aos seus trabalhos, é conhecido como o método da "escola italiana", uma abordagem histórica (não historicista), que se move sobre um solo duramente filológico como base propedêutica necessária para uma exegese lúcida e fundamentada, com um cuidado especial para as leituras de Nietzsche, 3 Cf. o aparato da Edição à seção VII, 1984 e 1986; MAZZINO. M. Compiti della ricerca nietzscheana oggi: il confronto di Nietzsche con la letteratura francese del XIX secolo. In: CAMPIONI, G. \& VENTURELLI, A. La "biblioteca ideale” di Nietzsche. Napoli: Guida Editorial, 1992, p. 269-282.

4 MONTINARI. M. Che cosa ha detto Nietzsche, [1975], editado por G. Campioni. Adelphi: Milano, 1999, p. 154. 
as fontes, a sua utilização frequentemente clarificante de aspectos que, deixados de lado, levam à cegueira - e um aguçado amor pelos detalhes que não derivam de uma supervalorização do fútil, mas de uma exigência pela verdade, como mostra a edição das cartas e das obras que Campioni dirigiu, antecipando - muitas vezes - os aparatos alemães e enriquecendo, nas novas edições dos fragmentos, com notas que são verdadeiros mananciais de referências e fontes.

Também nisso Campioni se revela um magistral aluno de Montinari, o qual advertia que o "mundo de Nietzsche - [...] é o mundo de suas experiências, dos acontecimentos e das correntes de pensamento de seu tempo, de suas reflexões históricas e críticas, de suas leituras (e que leitor foi Nietzsche!)" ". Isso não significa, como seguidamente receia-se, subtrair originalidade ao pensamento de Nietzsche fazendo dele simplesmente uma mistura das próprias leituras; mas, ao contrário, exatamente olhando para essas leituras é possível medir, com frequência, o grau de audácia que se perderia desconhecendo o preciso terreno de confrontação no qual Nietzsche cultiva o seu pensamento. Um exemplo ulterior disso, da decisiva importância do extratexto, é a necessidade, para poder enfrentar a filosofia de Nietzsche, mais do que aquela de outros autores, de uma "nítida consciência de que só se pode abarcar toda a complexidade do texto saindo dele" (p. 28).

E é saindo do texto, estudando as leituras com as quais realmente Nietzsche se confrontou, os autores hoje esquecidos que permanecem em suas páginas, emergem dos resultados historiográficos e exegéticos por outros lados inatingíveis. Começando com quanto podemos aprender pelo aprofundamento do confronto com Descartes, que a maioria das interpretações considera emblema de um racionalismo contrário ao gosto de Nietzsche, que sustentaria, pelo contrário, um raptus intelectual instintivo e romântico. O que Campioni mostra e demonstra, a partir da citação que o alemão escolhe como epígrafe da própria obra de libertação das metafísi-

5 Idem. 
Busellato, S.

cas schopenhaueriana e wagneriana - uma passagem cartesiana extraída do Discour de la méthode que abre Humano, demasiado humano - é um Nietzsche que se confraterniza com um Descartes modelado através de intermediários como Richet, Ribot, Brunetiére e que exalta o equilíbrio, a clareza e o método, entrincheirando-se do lado de um iluminismo da tolerância, adversário dos fanatismos obscurantistas, que tem o seu mais sereno emblema em Voltaire. Um iluminismo que, para Nietzsche, define uma concepção de clássico que se opõe ao romântico, nutrindo-se de uma tradição que se refaz, uma vez mais, ao sol mediterrâneo do humanismo italiano e conduz à sutileza psicológica meridional, desconhecida na Alemanha, por exemplo, de um Stendhal.

A análise da interpretação cartesiana se oferece como possibilidade de desvelamento de um Nietzsche realmente longe do misticismo germânico irracionalista de algumas interpretações que, apesar de antigas, nolens volens continuam irradiando distorções, como aquelas "mitológicas" de Bertram ou as "heroicas" de Baeumler, mostrando, ao contrário, uma figura moderada, consequente, amante do "piano" e do "adagio" oferecidos pelo Clássico, um Nietzsche para o qual é evidente "a superioridade do século caracterizado pela "razão de Descartes"” (p. 75).

O mesmo semblante nietzschiano, marcadamente mais do lado do equilíbrio do que do excesso, é aquele que emerge da análise do confronto com Renan, que dá condições de embrenhar-se numa selva de questões decisivas do pensamento de Nietzsche como aquelas de caráter religioso, político e sociológico. A leitura que ele faz do francês no curso dos anos, revela-se logo de início bem diferente daquela wagneriana, aliás, distante desta à medida que o professor de Basiléia acolhe muitas posições críticas do colega Burckhardt, que revela ser para Nietzsche um verdadeiro antídoto crítico ao germânico wagnerismo centrado sobre o autoritarismo do "Gênio-tirano" (este é um decisivo aglomerado conceitual ao qual Campioni, em parceria com o saudoso Sandro Barbera, 
CAMPIONI, Giuliano. Nietzsche e o espiríto latino.

dedicou um estudo específico, Il genio tiranno. Ragione e dominio nell'ideologia dell'Ottocento: Wagner, Nietzsche, Renan, publicado em 1983 e republicado em 2010).

Aparecem nessa via algumas características claras de Nietzsche e muitas vezes esquecidas, como o antibelicismo e o antinacionalismo que considerava a vitória militar como uma imposição bárbara que não tem nada a ver com o espírito e com a cultura, que é a sua mais alta expressão; ou a tentativa de reagir àquele mesmo vazio que se abria diante da profunda crise que a segunda metade do século XIX conheceu, em relação à qual outros filósofos quiseram indicar a resposta no sentido de massificação, abnegação e sacrifício de si mesmos - solução que Nietzsche pressentiu de longe ser uma perigosa trilha que poderia levar exatamente aos horrores do fanatismo sanguinário que o século XX conheceu.

Desse modo, de um Nietzsche sentado à escrivaninha, com a intenção de meditar e a tomar distância em relação às páginas de Renan, e tendo consigo outros textos esclarecedores (Boueget, Barbey d'Avrevilly, Anatole France, Dostojevsky em tradução francesa e mediado por autores também franceses), torna-se possível medir a natureza real, a estratégia filosófica à qual é orientado e o significado sintético-conceitual do famigerado Além-do-homem e apanhar com mais clareza os contornos através da comparação com os devas renanianos, semelhantes ao filosofema nietzschiano, mas só superficialmente. Ambos são tentativas de "dar uma solução superior" a uma crise de nihilismo epocal, mas a tentativa de Nietzsche revela ser mais audaz e cautelosa ao mesmo tempo. Audaz porque rejeita qualquer tendência coercitiva que apele a substitutos metafísicos e violentadores (as "sombras de Deus", temática crucial que em outras obras Campioni teve o mérito de colocar sob a atenção dos intérpretes), mas também cautelosa porque revela ser uma proposta antropológica de um tipo de homem que faça do equilíbrio uma preciosa virtude, conforme a afirmação no fragmento sobre o nihilismo europeu, incompreensível de outro modo, no qual lemos: 
"Quais são os homens que se revelam então os mais fortes? Os mais moderados [die Mäßigsten], aqueles que não têm necessidade de artigos de fé extremos, aqueles que não só admitem, mas também amam uma boa parte de casualidade, de absurdidade, aqueles que sabem pensar sobre o homem com uma considerável redução do seu valor, sem por isso tornar-se pequenos e fracos" $"$

Se a imagem do Nietzsche teutônico ainda permanece, isso se deve a alguns elementos (muitas vezes equivocados) que pertencem ao seu período wagneriano, e que já ele mesmo viu-se obrigado ainda em vida a escrever Nietzsche contra Wagner, na enfastiada tentativa de dissipá-los. Campioni adentra-se assim na tentativa de esclarecer os entornos, abandonados em seguida, e as precoces tomadas de distância em relação ao autor de Parsifal. Faz isso seguindo os vestígios, totalmente preteridos, da literatura secundária, abordando os temas da "irredutível aversão à cultura romana [latina]" (p.162) wagneriana e oferecendo uma contribuição nova e preciosa aos estudos nietzschianos com a análise da interpretação e da relação que o filósofo alemão manteve com o Renascimento.

É exatamente no ato de valorizar o Renascimento, colocado como continuação do Humanismo e antecipação do Iluminismo, que se desenrola grande parte da oposição nietzschiana à cultura alemã, "a aposição do filorromano Nietzsche com Wagner, o Germânico" (p. 201). A essa tomada de posição concorrem autores específicos com os quais Nietzsche tece um relacionamento "complexo que nada tem de passivo" (p. 233) dos quais, entre tantos, Taine, Burckhardt, Stendhal, Bourget, Gebhart. Com eles, reúne e posiciona os representantes de um espírito latino solar capaz de dissipar o nevoeiro do obscurantismo alemão: Petrarca, Boccaccio, Petronio, Michelangelo, Cesare Borgia, o abade Galiani e ainda outros. Não só isso, mas da análise dessas figuras torna6 Nachlass/FP 5 [71], verão de 1886 - outono de 1887, § 15, datado em 10 junho de 1887 e conhecido como Fragmento de Lenzer Heide. Por uma sua interpretação, CAMPIONI, G. Il "sentimento del deserto". Dalle pianure slave al vecchio continente. In: F. Nietzsche, Il nichilismo europeo. Milano: Adelphi, 2006, p. 47-60. 
se possível também compreender corretamente alguns dos temidos elementos nietzschianos como a Raubthier, o Gewaltmensch ou a relação com Gobineau, libertando o filósofo de uma imagem que, reduzindo-o "a ser tão somente um 'professor de energia' ou um profeta da 'religião da força' desemboca imediatamente no grotesco e no mau gosto" (p. 234).

Não terminam aqui os resultados que a pesquisa sobre o Nietzsche "latino" consegue trazer à luz, e são tão numerosos e variegados que seria inútil uma tentativa de resumi-los pretendendo a exaustividade. Esses resultados estendem-se desde a descoberta de fontes até o momento pouco investigadas ou ignoradas (por exemplo: Michelet, Richepin, De Custine, Lemaître, Desprez, Diderot etc.), as quais permitem observar e compreender o que acontece nos bastidores do que Nietzsche coloca filosoficamente em cena, em comparações iluminantes com autores importantes e interpretações que fazem emergir em toda a sua riqueza a meditação nietzschiana (Goethe, Byron, Napoleone, Heine...) e que fornecem uma chave preciosa para entrar nas temáticas construtivas desta cena, como o pessimismo, a morte de Deus, os homens superiores do Zaratustra, aos quais são dedicadas análises impressionantes pela lucidez e pela capacidade explicativa.

Com esse texto Campioni não só inverte, sobre incontestáveis bases histórico-filológicas, a figura - canônica no amadorismo (e não só no amadorismo) - do Nietzsche germânico para oferecer-nos, ao invés, um espírito latino que permeia o autor tornando-o mais profundo, policromático, inteligente e inteligível, dotado de uma apaixonante complexidade que aumenta enormemente o prazer de estudá-lo - mas demonstra também que o especialismo nietzschiano exige como própria condição a saída do especialismo. Requer o enfrentamento da longa e por vezes fatigante viagem através do Dédalo de avenidas, ruas e ruelas que constituem a topografia da Cultura em sentido autêntico. Demonstra que, para ler corretamente uma página de Nietzsche, pode ser necessário ler inteiras 
Busellato, S.

estantes de bibliotecas. E ensina, enfim, que grandes resultados podem ser conseguidos também seguindo metodologicamente a cautela e deontologicamente a modéstia; aquela mesma requintada e exigente modéstia que Montinari seguia quando dizia de si mesmo querer "ser um bom 'trabalhador', como um bom sapateiro faz bons sapatos"?.

Aclamado, por ocasião da sua aparição na França, como algo que entre os estudos nietzschianos revela ser "um acontecimento" (Le Rider); traduzido em alemão e em espanhol, é agora acolhido no Brasil como um estudo que "apresenta uma nova face do autor de Zaratustra; bem mais, torna possível que ele fale outra vez com a própria voz. Haveria maior contribuição para promover o avanço dos estudos nietzschianos?"я

Portanto, é fácil prognosticar ao Nietzsche de Campioni, aqui no Brasil também, uma ampla difusão, como acontece naturalmente aos raros textos capazes de amadurecer nas bases os parâmetros interpretativos com os quais lemos um "clássico".

\section{Referências bibliográficas}

CAMPIONI, G. Il "sentimento del deserto". Dalle pianure slave al vecchio continente. In: F. Nietzsche, Il nichilismo europeo. Milano: Adelphi, 2006.

MAZZINO. M. Compiti della ricerca nietzscheana oggi: il confronto di Nietzsche con la letteratura francese del XIX secolo. In:. CAMPIONI, G. \& VENTURELLI, A. La "biblioteca ideale" di Nietzsche. Napoli: Guida Editorial, 1992.

MONTINARI. M. Che cosa ha detto Nietzsche, [1975], editado por G. Campioni. Adelphi: Milano, 1999.

Resenha recebida para publicação em 30/08/2016.

Resenha aceita para publicação em 31/10/2016.

7 Carta de M. Montinari a G. Colli, 29 de setembro de 1967.

$8 \mathrm{~S}$. Marton, Apresentação à edição brasileira, p. 18.

126| Cad. Nietzsche, Guarulhos/Porto Seguro, v.37, n.3, outubro/dezembro, 2016. 